\title{
Ni- and Co-Based Superalloys and their Coatings
}

\author{
Jonathan Cormier
}

Institut Pprime, UPR CNRS 3346, Physics and Mechanics of Materials Department, ISAE-ENSMA, 1 Avenue Clément Ader, BP 40109, 86961 Futuroscope-Chasseneuil, France; jonathan.cormier@ensma.fr

\section{Introduction and Scope}

Nickel- and Cobalt-based superalloys are state-of-the art materials for the manufacturing of components in the hottest sections of aero-engines and land-based power generation gas turbines. They are typically used for the manufacturing of combustion chambers, high- and low-pressure turbine blades and vanes, shrouds and casings, among other components. Despite the recent introduction of new materials (e.g., Ceramic Matrix Composites and Titanium Aluminides) to replace Ni-based superalloys for some components in the most advanced gas turbines, $\mathrm{Ni}$ - and Co-based superalloys are still, and will be widely, used for high-temperature parts.

Due to the increase of the operating temperatures and/or the complexity of geometries of components made of Ni-based superalloys in gas turbines, new issues related to their durability in service or to their processing have been identified. Therefore, the aim of this Special Issue is to provide an outlook on recent research activities related to the processing and use of Ni-based superalloys and their coatings during service.

\section{Contributions}

The present Special Issue is composed of seven articles related to alloy development [1], mechanical behavior during forging of polycrystalline alloy [2], a coating deposition process [3], microstructure in an additively manufactured Ni-based superalloy [4], mechanical behavior during close-to-service conditions of cast alloys [5,6] and repair of a cast alloy [7].

In more detail, the effect of the Niobium/Titanium ratio on age hardening behavior has been investigated by Hisazawa et al. [1] using different alloys whose compositions have been selected through an "Alloy-by-Design" approach formerly developed in Roger Reed's group. Microstructural stability and the size distribution evolution of precipitates as a function of the aging time at $1123 \mathrm{~K}$ have more specifically been investigated.

The flow stress and dynamic recrystallization behaviors in the $1223 \mathrm{~K}$ to $1423 \mathrm{~K}$ temperature range have been investigated by Zhang et al. in a polycrystalline strengthened alloy [2]. Based on dislocation density theory and dynamic recrystallization kinetics, the proposed constitutive modeling approach provides a satisfying modeling of the observed behavior.

The processing parameters for the deposition of $\mathrm{Cr}_{2} \mathrm{AlC}$ MAX phase as a coating by a sputtering technique have been investigated in the paper by Naveed et al. [3]. This type of MAX phase has been demonstrated recently by Smialek to be an efficient coating for the protection against corrosion of Ni-based disk alloys or a potential candidate for new-generation of bond coats in thermal barrier coating systems. Columnar $\mathrm{Cr}_{2} \mathrm{AlC}$ coatings have been achieved by Naveed et al. [3] and the effect of processing parameters on coating thickness, hardness, and elastic moduli has been investigated. 
The microstructure of a CMSX-4 like Ni-based superalloy produced by Selective Electron Beam Melting (SEBM) has been investigated by Parsa et al. [4]. According to high resolution characterizations by SEM and TEM, it is shown that this type of processing route generates a microstructure that is, overall, similar to what can be observed after directional solidification using a standard Bridgman process but with a refined dendritic structure and a columnar structure (a DS structure) at a larger length scale. For SEBM specimens built with a fast cooling rate, a high density of dislocation is observed, indicating a very high level of internal stresses that may have technologically important repercussions on the mechanical behavior/durability of parts.

Wear behavior of René 80 alloy has been investigated at $600^{\circ} \mathrm{C}$ and $800^{\circ} \mathrm{C}$ by Lavella [5]. This type of investigation is highly relevant when considering durability in fatigue-fretting of blade roots during service. In his study, Lavella has shown that a lower friction coefficient is obtained at $800{ }^{\circ} \mathrm{C}$ and possible extrapolation up to $1000^{\circ} \mathrm{C}$ can be expected.

The evolution of creep life at $980^{\circ} \mathrm{C} / 300 \mathrm{MPa}$ in multi-perforated specimens made of DD6 second generation Ni-based single crystalline superalloy has been investigated by $\mathrm{Xu}$ et al. [6]. Both experimental and numerical approaches have been undertaken to be able to optimize film-cooling holes spatial distribution along a blade profile, from a mechanical point of view. Using a crystal plasticity approach, the authors have been able to account for the crack initiation sites and morphology of fracture surface observed experimentally.

Finally, the effect of Hot Isostatic Pressing (HIP) on crack healing in laser repaired (Laser Metal Deposition process) CM247LC alloy has been investigated by Hsu et al. [7]. It is shown that using proper HIP process parameters, all types of cracks can be closed. Moreover, a better chemical homogeneity is achieved, probably improving mechanical properties of repaired CM247LC.

\section{Conclusions and Outlook}

According to the variety of topics treated in this Special Issue, it can be seen that new activities and questions are emerging regarding design and applications of $\mathrm{Ni}$ - and $\mathrm{Co}$-based superalloys for aeronautical applications. It is anticipated that new problems at each stage of the processing route(s) and/or service use and/or repair of components made of Ni-based superalloys will appear in the next five to ten years thanks to their massive introduction in new industrial fields such as the automotive one (use of cast superalloys for turbochargers, gas collectors, ... ).

As a guest editor, I would like express my gratitude to all the contributing authors for making this Special Issue a valuable reference source on this topic. I also want to extend my special thanks to the Metals editorial team, and in particular to Natalie Sun, for her assistance and support during the preparation of this Special Issue.

Conflicts of Interest: The author declares no conflict of interest.

\section{References}

1. Hisazawa, H.; Terada, Y.; Adziman, F.; Crudden, D.; Collins, D.; Armstrong, D.; Reed, R. The Effect of Nb/Ti Ratio on Hardness in High-Strength Ni-Based Superalloys. Metals 2017, 7, 71. [CrossRef]

2. Zhang, P.; Yi, C.; Chen, G.; Qin, H.; Wang, C. Constitutive Model Based on Dynamic Recrystallization Behavior during Thermal Deformation of a Nickel-Based Superalloy. Metals 2016, 6, 161. [CrossRef]

3. Naveed, M.; Obrosov, A.; Zak, A.; Dudzinski, W.; Volinsky, A.; Weiß, S. Sputtering Power Effects on Growth and Mechanical Properties of Cr2AlC MAX Phase Coatings. Metals 2016, 6, 265. [CrossRef]

4. Parsa, A.; Ramsperger, M.; Kostka, A.; Somsen, C.; Körner, C.; Eggeler, G. Transmission Electron Microscopy of a CMSX-4 Ni-Base Superalloy Produced by Selective Electron Beam Melting. Metals 2016, 6, 258. [CrossRef]

5. Lavella, M. Contact Properties and Wear Behaviour of Nickel Based Superalloy René 80. Metals 2016, 6, 159. [CrossRef] 
6. Xu, Y.; Sun, W.; Dai, W.; Hu, C.; Liu, X.; Zhang, W. Experimental and Numerical Modeling of the Stress Rupture Behavior of Nickel-Based Single Crystal Superalloys Subject to Multi-Row Film Cooling Holes. Metals 2017, 7, 340. [CrossRef]

7. Hsu, K.-T.; Wang, H.-S.; Chen, H.-G.; Chen, P.-C. Effects of the Hot Isostatic Pressing Process on Crack Healing of the Laser Repair-Welded CM247LC Superalloy. Metals 2016, 6, 238. [CrossRef] 